Sammlung Metzler

Band 289 
Für Renate 


\section{Matthias Luserke}

\section{Robert Musil}

Verlag J.B. Metzler Stuttgart - Weimar 
Die Deutsche Bibliothek - CIP-Einheitsaufnahme

Luserke, Matthias:

Robert Musil / Matthias Luserke.

- Stuttgart ; Weimar : Metzler, 1995

(Sammlung Metzler ; Bd. 289)

ISBN 978-3-476-10289-8

NE: GT

ISSN 0558-3667

ISBN 978-3-476-10289-8

ISBN 978-3-476-03986-6 (eBook)

DOI 10.1007/978-3-476-03986-6

\section{SM 289}

Dieses Werk einschließlich aller seiner Teile ist urheberrechtlich geschützt. Jede Verwertung außerhalb der engen Grenzen des Urheberrechtsgesetzes ist ohne Zustimmung des Verlages unzulässig und strafbar. Das gilt insbesondere für Vervielfältigungen, Übersetzungen, Mikroverfilmungen und die Einspeicherung und Verarbeitung in elektronischen Systemen.

(C) 1995 Springer-Verlag GmbH Deutschland

Ursprünglich erschienen bei J.B. Metzlersche Verlagsbuchhandlung und Carl Ernst Poeschel Verlag GmbH in Stuttgart 1995 
»Willst Du Musil? Musil-musil?

Oder magst Du lieber Walzel . . ? « (MoE, S. 2127).

»es ist mir sehr unangenehm, daß man real interpretirt « (Br I, S. 24). 


\section{Vorbemerkung}

Diese Einführung in Leben und Werk Robert Musils wendet sich nicht an die Insider. Das Buch sucht seine Leser und Leserinnen dort, wo Neugier oder Unverständnis, Kritik oder Sympathie den Blick auf die Texte Robert Musils gelenkt haben. Dem Konzept der Reihe entsprechend, versteht sich das Buch als Einführung, als Möglichkeit, sich der Wirklichkeit der Literatur am Beispiel Robert Musils zu nähern. Ein Plädoyer für Robert Musil zu schreiben heißt, ein Plädoyer für die Bedeutung der Literatur zu halten.

Ich danke herzlich für die Hilfe bei der Materialbeschaffung Frau Dr. Annette Daigger von der Arbeitsstelle für Österreichische Literatur und Kultur/Robert Musil-Forschung an der Universität Saarbrücken.

Saarbrücken, im September 1994

\section{Zur Zitierweise:}

Sämtliche Texte von Robert Musil mit Ausnahme des Mann obne Eigenschaften, der Tagebücher, der Briefe und der Dissertation werden nach folgender Ausgabe zitiert: Robert Musil: Gesammelte Werke in neun Bänden. Hgg. v. Adolf Frisé. Reinbek b. Hamburg 1978. [Zitiert als GW mit Band- und Seitenzahl].

Der Roman Der Mann obne Eigenschaften wird nach folgender zweibändigen Sonderausgabe zitiert: Robert Musil: Der Mann obne Eigenschaften. Hgg. v. Adolf Frisé. Neu durchgesehene u. ergänzte Aufl. Sonderausgabe. 2 Bde. Reinbek b. Hamburg 1984. [Zitiert als MoE mit Seitenzahl; diese Ausgabe ist textund seitenidentisch mit den Bänden 1-5 der Gesammelten Werke]. 


\section{Inhalt}

Vorbemerkung ............... VI

1. Einleitung $\ldots \ldots \ldots \ldots \ldots \ldots \ldots$

2. Biographische Skizze . . . . . . . . . . 4

3. Die Verwirrungen des Zöglings Törleß . . . . . 14

4. Erzählungen und Dramen . . . . . . . . . . 35

4.1 Vereinigungen ............. . 37

4.2 Die Schwärmer . . . . . . . . . . . . . . . 46

4.3 Vinzenz und die Freundin bedeutender Männer . 51

4.4 Drei Frauen . . . . . . . . . . . . . . . 58

5. Die Essays . . . . . . . . . . . . . . . 67

6. Nachlaß zu Lebzeiten . . . . . . . . . . . . . . 77

7. Der Mann ohne Eigenschaften . . . . . . . . . 83

8. Bibliographie . . . . . . . . . . . . 110

9. Wortregister zum Mann ohne Eigenschaften . . . 134

10. Namen- und Werkregister . . . . . . . . . . 141 Angaben zum Autor . . . . . . . . . . . . . . 144 